\title{
Comments on Current Situation of Leisure Sports Public Service in Urban Community and Countermeasures Therefore
}

\author{
Hongchun Jia, Songbo He* \\ College of physical education, Beihua University, Jilin Jilin, 132021, China \\ ${ }^{*}$ Corresponding author
}

Key words: Urban, Community leisure, Sports, Public service.

\begin{abstract}
Urban community leisure sports put forward higher requirements for public service. Under this context, measures should be taken to improve the public service quality of community leisure sports and management level. This paper aims to focus on the analysis of the current situation of public service of urban community leisure sports, and make positive comments by putting forward proper countermeasures, to guarantee the normalization of duty fulfillment.
\end{abstract}

\section{Introduction}

With the rapid progress of urbanization, urban community construction also develops rapidly, which promotes the strategic development of a well-off society in an all-around way, and arouses the enthusiasm of Chinese community residents for sports development. In the process of constant exploration and practical construction, it is supposed to put forward higher requirements for current construction of urban community leisure sports, and actively made improvement in various aspects, to promote the completeness of infrastructure of China.

\section{Current Situation of Leisure Sports Public Service in Urban Community}

\section{Current Management Situation of Community Leisure Sports Organization}

The current management situation of community leisure sports organization is mainly reflected in four aspects. Firstly, the scope of responsibility of urban leisure sports organization is not clearly defined. An organization is the most important carrier in the carrying out of activities, and the community leisure sports organization can provide necessary basic conditions for community leisure sports activities. Currently, most community leisure sports organizations are established by the common people or operational clubs, which is away from the management of community government organizations. Thus, there are a lot of efforts can be made. Besides, the responsibilities of community sports organization, the subject of management, are not completely manifested. Some community leisure sports organizations also have not made proper policies and regulations, so that many problems of community leisure sports management remain unsettled. Secondly, the departments in community don't work consistently. The departments are divided based on administration factors, and dependent from each other in respect of manpower, material, and finance, keeping the departments from communicating with each other, and impeding the fulfillment of community leisure sports public service. Thirdly, the people-oriented development idea is not implemented, so that the construction of community leisure sports public service ceases to advance. With the constant improvement of urban economic level, many urban communities have built sporting facilities and recreational space, but some sporting facilities don't meet the needs of residents at all, and restrain the supply of public service leisure sports products. Fourthly, there is no sound policy on community leisure sports public service, or specific laws and regulations thereon. Policies and legal system can play an important role in the construction of community leisure sports, greatly guaranteeing the government, society and individuals, and promoting the healthy development of community leisure sports public service. Yet the government doesn't put forward to construct unified policy, laws or 
regulations, nor science is not employed for guiding practical operation, which impedes the healthy development of community leisure sports public service.

\section{Current Situation of Funds and Facilities of Community Leisure Sports}

The current development situation of funds and facilities of community leisure sports is as below. The funds for community leisure sports mainly come from government subsidy, fund raising and social donation. Some governments have no budget to provide subsidy, and some governments only give a little funds to purchase sporting facilities, which greatly hinders the development of community residents' leisure sports activities. Besides, the public sporting facilities in community are not enough. With the constant advance of national fitness program, many cities provide places for the development of community leisure sports, and take measures to promote cultural construction. Nevertheless, the fitness and leisure needs of urban residents still cannot be fully addressed. Presently, most sports grounds and facilities are built in schools, which are available in limited time, and the using functions also are limited. All these hinder the healthy development of community leisure sports activities ${ }^{[1]}$. To sum up, that the sports ground and facilities are not enough to fully address the fitness needs of residents is the main reason.

\section{Current Situation of Professional Talents of Community Leisure Sports}

The current development situation of professional talents of community leisure sports will be analyzed from three aspects. Firstly, there are inadequate instructors of community leisure sports, they slack on their duties, and are inferior in respect of cultural quality. Presently, there are a few sports instructors in China and most instructors are not well-educated but only have received senior high school education at most, who cannot address the fitness and leisure needs of people. Secondly, sports instructors are old, and take up the post in part-time mode, which actually provide low efficient services. Though old instructions are more experienced in management, they are retired work and take up the post in part-time mode, and the number of instructions decreases constantly, which reduces the instruction efficiency of leisure and fitness in community leisure sports, and results in an unordered management. Thirdly, not all community residents feel satisfied with the sports instructors. Most community residents show satisfaction for giving face, which results in that instructors feel good about themselves and make no attempt to make progress, and the service quality of community leisure sports is lowered.

\section{Countermeasures for Urban Community Leisure Sports Public Service}

To raise the consciousness and level of urban community leisure sports public service, and provide abundant high-quality urban community leisure sports public service to community residents, it is supposed to build a sound urban community leisure sports public service system. In general case, the governments should transform their functions from governance to administration, and coordinate with enterprises in rationally planning urban community leisure sports environment, to build distinctive leisure sports brands, and improve the level and quality of urban community leisure sports public service on the whole. Besides, measures also should be taken from the aspects of service, products, management and channels, to ensure high efficiency in the construction of public service. Secondly, it is supposed to establish an effective guarantee mechanism and made rational decisions, properly use social resources in the construction of community leisure sports public service, and build a diversified multi-layer supply system, to address the needs of social groups in an all-around way. Countermeasures are put forward from the following aspects ${ }^{[2]}$.

\section{Establishment of Related Policies, Laws and Regulations}

The establishment of related policies, laws and regulations can guarantee the construction of urban community leisure sports public service system. Concerning policy establishment, the state and related governments are supposed to consider about the development based on the characteristics of 
urban community leisure sports and urban development tendency, and ask sports scholars and legal experts for opinions on the needs and conditions of urban community leisure sports in China, so as to make effective policies, laws and regulations on the premise of maintaining the rights and interests of entertainment of residents. This development tendency will promote the self-propelled development and legal construction of urban community leisure sports public service. Besides, a hearing system, and a performance evaluation system should be established for the implementation of urban community leisure sports public service. It is mainly supposed to plan the supply form of urban community leisure sports public service, and effectively supervise the expenditures on sites, organization form of activities, and service level and quality, so as to truly implement the construction of urban community leisure sports public service.

\section{Transformation of Sports Ground}

It is supposed to develop and transform sports ground of community leisure sports. Specifically, firstly, related governments should plan and design the development and transformation of community leisure sports ground first, increase capital input in the construction of urban community leisure sports public service by making full use of the resources of communities such as the geographic location and cultural environment, and harmonize community environment with the construction conditions by means of development and transformation. In the process of construction and development, a large number of urban community leisure sports facilities can be increased, and the quality of urban community leisure sports facilities can be improved. Besides, the existing service facilities in urban community should be made full use of, such as public facilities in parks, sporting facilities in schools and enterprises and public institutions, etc., related policies should be referred to, and scientific planning should be made during transformation and development, so as to achieve national sports development and comprehensive progress of project implementation, and provide constructive suggestions on urban community leisure sports public service of residents. Lastly, it is supposed to strengthen management and using of urban community leisure sports public service facilities by, for example, scheduling the opening hours of public facilities, operating public sporting facilities in a limited way, and providing limited services, so as to realize both public benefit and operation of urban community leisure sports public service with the support of government subsidy [3].

\section{Training of Professional Talents}

Greater efforts should be made to train professional talents, to address the demand for professional talents in urban community leisure sports public service. Urban community leisure sports mainly relates to leisure sports facilities and leisure sports organizations, and constitutes a part of the tertiary industry of city. Social sports instructors are the communicators and organizers of urban community leisure sports public service, can contribute to the positive progress of society in respect of community sports development of China, and give instructions to community residents to locate sports ground, so as to play an important role in improving the quality of urban community leisure sports public service. Under this context, in order to promote effective and efficient development of the construction of urban community leisure sports public service, professional management and high-level technicists. Thus, talent training becomes a main content of the development and service rendering ${ }^{[4]}$. Talent training can be carried out in various ways or channels, which can address the development needs of community resident. Besides, it is supposed to strengthen the management and employment of community sports instructors by establishing a sound performance evaluation mechanism and an incentive mechanism, etc. For the management thereover, related organizations can be established to provide regular training on professional knowledge and skills to instructors, so as to improve the quality of urban community leisure sports public service on the whole. Besides, it is supposed to input more resources in the cultivation of volunteers of urban community leisure sports public service, who can facilitate physical education of sports knowledge, and relieve the shortage of sports instructors in China. 


\section{Multi-channel Fund Raising}

Fund raising from various channels can financially guarantee the construction of urban community leisure sports public service, because abundant capital is an important guarantee for the fulfillment of urban community leisure sports public service. Hence, the government should make special fiscal policy, and offer strong financial support, so as to financially help the construction of public welfare and non-profit project. For the implementation of urban community leisure sport public service, the responsibilities of the government and the market should be clearly defined, and some public goods and their service forms should be classified. In general case, the using of funds is under the control of the government and operated in the market. Besides, incentive policies should be made to encourage enterprises to give donations to public welfare sports undertakings, so as to enrich the capital investment in sports development. In other words, the donated funds can make up the shortage of government input and subsidy ${ }^{[5]}$. Besides, the cities should strengthen their construction of urban community leisure sports public service in proper ways. For example, leisure sports service activities on holidays and festivals can be organized by using public sports facilities in business places or public places to render leisure sports service, and facilitate community residents in finding proper sport ground.

\section{Building of Public Information Service Platform}

The building of a sound public information service platform can improve the urban community leisure sports public service level. For the building and perfection of the platform, firstly, urban community residents should develop a consciousness of leisure sports activities, master knowledge and skills related to leisure sport, and be educated to lead a healthy life in a scientific living style. To this end, the knowledge on urban community leisure sport should be collected and sorted, and published via the public network service system. Through the system, community residents can learn about information on community leisure sports public service, policies, knowledge of health maintenance, activity news, and technical guidance, to facilitate their activities and development. Through the system, community residents can obtain what they desire to learn about, and put forward constructive opinions and suggestions, so that related service staff can timely give response to community residents after making scientific and rational decisions, and make effort to improve the service quality and level.

\section{Conclusion}

Public service is largely concerned about by Chinese government, which is mainly expressed by public goods, can facilitate the public facilities construction in both urban and rural areas, and promote employment, and cultural and health development. Thus, the current situation of urban community leisure sports public service was analyzed, and positive countermeasures were put forward in this paper, with a hope to accelerate urbanization and promote the establishment of public service system.

\section{Acknowledgments}

This paper is a project of Physical Education Office of Jilin Province, numbered 2015015.

\section{References}

[1] Chen Xinsheng, Chu Jijun. Current Situation of Urban Community Leisure Sports Public Service and Countermeasures therefor. Journal of Xi'an Physical Education University, 2011, 28(1): 29-33. 
[2] Wu Yulei. A Study on Current Development Situation of Urban Community Sports Public Service System in Western Shandong and Countermeasures therefor. Qufu Normal Univerity, 2012.

[3] Li Yunong. A Study on Countermeasures for Accelerating Community Leisure Sports Public Service of Changsha-Zhuzhou--Xiangtan City Group.Modern Enterprise Education, 2014(24): 565-565.

[4] Zhao Jingui. Brief Discussions on the Necessity and Urgency of Developing Community Leisure Sports Public Service System. Technical of Practical Fighting, 2012,4(12):33-34.

[5] He Xiaozhong. Brief Analysis of Urban Community Leisure Sports Service.Nei Jiang Science \& Technology,2015,36(2):139,127. 